\title{
The Issue of Peer-Review
}

Alexandre Rezende Vieira

Editor in Chief

Department of Oral Biology, University of Pittsburgh School of Dental Medicine, Pittsburgh PA, USA

It is widely accepted that peerreview is the process that validates the published scientific literature. However, it is known to be inconsistent, biased, onerous, slow, and expensive. The typical journal, such as Dentistry 3000, follows these common steps:

1. The editor, upon receiving a manuscript submission, will decide if the paper should be peer-reviewed. If the decision is "no," the editor will reject the paper. If the decision is yes, the process of inviting individuals to revise the manuscript begins.'

2. The peer-reviewers provide a general impression about the paper. Typically, these include suggestions to revise the paper and resubmit.

3. The editor receives from the authors a revised version of the manuscript and he-she will decide if the new version is acceptable or not, and often will send it to peer-review again, trying to have the same reviewers look at the revised manuscript. This process can have multiple iterations with the authors.

This peer-review process gives credibility to publications and is not only used for defining which papers should be published, but also for making decisions on funding of research projects. Additionally, journals quite often suggest to authors their acceptance rates, some proud to reject $60 \%$ or more of the submissions without even sending to peer-review. Journals define themselves, not only thematically, but also on the types of papers they publish. Many journals emphasize originality and positive results. It is more difficult to publish the results of a well-designed clinical trial when they are negative.
Citation: Vieira AR. (2016) The Issue of Peer Review. Dentistry 3000. 1:a001 doi:10.5195/d3000.2016.65

Received: November 30, 2016

Accepted: December 12, 2016

Published: December 14, 2016

Copyright: (C2016 Vieira AR. This is an open access article licensed under a Creative Commons Attribution Work 4.0 United States License.

Email: arv11@pitt.edu (cc) BY ULLS D-Sorte
New articles in this journal are licensed under a Creative Commons Attribution 4.0 United States License.

This journal is published by the University Library System, University of Pittsburgh as part of its D-Scribe Digital Publishing Program and is cosponored by the University of Pittsburgh Press. 